\title{
Switchable Aromaticity in an Isostructural Mn Phthalocyanine Series Isolated in Five Separate Redox States
}

\author{
Camden Hunt, ${ }^{\dagger}$ Madeline Peterson,${ }^{\dagger}$ Cassidy Anderson, ${ }^{\dagger}$ Tieyan Chang, ${ }^{\dagger}$ Guang Wu, ${ }^{\dagger}$ Steve Scheiner, $\|$ \\ and Gabriel Ménard*,† \\ ${ }^{\dagger}$ Department of Chemistry and Biochemistry, University of California, Santa Barbara, California 93106, United States \\ "ChemMatCARS, University of Chicago, Argonne, Illinois 60493, United States \\ "Department of Chemistry and Biochemistry, Utah State University, Logan, Utah 84322, United States
}

\begin{abstract}
The synthesis and characterization of a new phthalocyanine $(\mathrm{Pc})$ Mn-nitride complex, $\left({ }^{\mathrm{OEt}} \mathrm{Pc}\right) \mathrm{MnN}\left(\mathbf{2} ;{ }^{\mathrm{OEt}} \mathrm{Pc}=\right.$ $1,4,8,11,15,18,22,25$-octaethoxy-Pc), as well as its stable, readily accessible oxidized $\left(\mathbf{2}^{+}\right.$and $\left.\mathbf{2}^{\mathbf{2}}\right)$ and reduced $\left(\mathbf{2}^{-}, \mathbf{2}^{\mathbf{2}}\right)$ congeners is reported. This unique isostructural series displays switchable aromatic character spanning the aromatic $(\mathbf{2})$, non-aromatic $\left(\mathbf{2}^{\mathbf{2}}\right)$, and antiaromatic $\left(\mathbf{2}^{\mathbf{2}}\right)$ triad, in addition to the open-shell radical states $\left(\mathbf{2}^{+}, \mathbf{2}^{-}\right)$. All complexes were structurally characterized and displayed significant structural distortions at the redox extrema $\left(2^{2+}, 2^{2-}\right)$ consistent with proposed [16 or 18]annulene $\pi$ ring circuit models. Spectroscopic and computational studies further support these models. This isolated, fully characterized, isostructural series spanning five redox states $\left(\mathbf{2}^{2+}, \mathbf{2}^{+}, \mathbf{2}, \mathbf{2}, \mathbf{2}^{\mathbf{2}-}\right)$ is unique in both the Pc and related macrocyclic (ex. porphyrinoids) literature and may offer direct insight into structural-electronic correlations driven by switchable aromaticity.
\end{abstract}

\section{INTRODUCTION}

Hückel's $(4 n+2) \pi \mathrm{e}^{-}$rule is conventionally used to predict the aromatic character of cyclic, planar, $\pi$-conjugated compounds. However, in extended aromatic systems this rule often gives unsatisfactory predictions of in/stability and deviations from the tenets of Hückel's rule, such as the requirement for planarity, become more common. ${ }^{1-3}$ In concert with this, macrocyclic platforms often adopt localized internal $\pi$ circuits within the extended $\pi$ manifold as exemplified by Vogel's [18]annulene/ $18 \pi$ $\mathrm{e}^{-}$model applied to porphyrins ${ }^{4-5}$ and related phthalocyanins (Pc) (Figure 1a-b). ${ }^{6}$ An alternative but less common model involving the dianionic ([16]annulene) $)^{2-}$ substructure has also been proposed as the primary aromatic circuit, particularly for metalloporphyrins (Figure 1c). ${ }^{5,7}$ While the annulene model aids in understanding the complexity of aromaticity in large macrocyclic systems, it is not a complete description, particularly regarding correlations between local and macrocyclic ring currents, both demonstrated to be important considerations when describing total aromaticity., 8-10

The inherent interplay of resonance circuits and electronic properties has resulted in the development of several structure/function relationships between aromaticity and electronic behavior in large, conjugated systems. ${ }^{11}$ Notably, the correlation between aromaticity and conductance has been well described by many and may have important implications for the development of next generation organic electronic devices. ${ }^{12-15}$ In contrast, "switchable" aromatic character may be used to design single-molecule transistors and other molecular-scale electronic gates. A molecular macrocyclic platform spanning separate aromatic states - and correlated structural perturbations may guide the development of such materials and their proper- ties. While redox-switchable aromaticity in macrocyclic platforms, such as porphyrinoids, has been studied, ${ }^{1}$ with several isolated discreet anti-aromatic or non-aromatic species reported, ${ }^{16-26}$ to the best of our knowledge, there are no known examples of a single stable, isostructural complex - either porphyrin or Pc-based, or other - isolated in multiple separate redox states, including radical states, and spanning the aromatic, non-aromatic, and anti-aromatic triad.

a)

THIS WORK

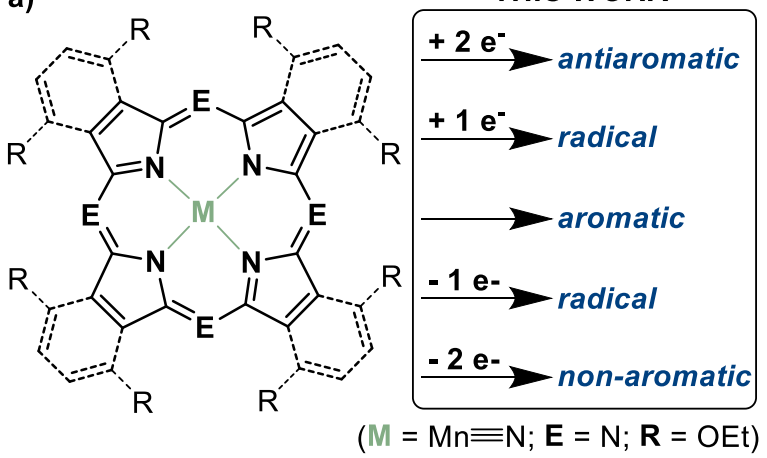

b)

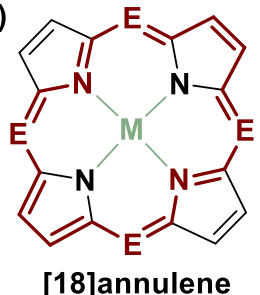

c)

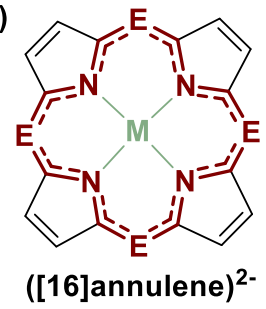

Figure 1. a) Depiction of porphine (solid lines), the parent molecule to porphyrins, and the related phthalocyanine (solid + dashed lines) coordinated to a generic metal (M). b) The [18]annulene/18 $\pi$ 
$\mathrm{e}^{-}$circuit, in bold. c) The dianionic ([16][annulene] $)^{2-} / 18 \pi \mathrm{e}^{-}$circuit in bold.

a)
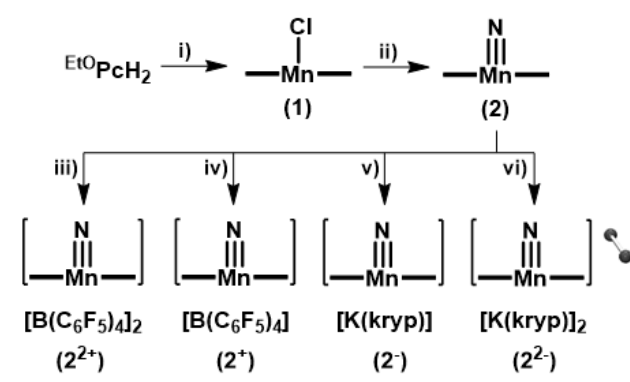

b)

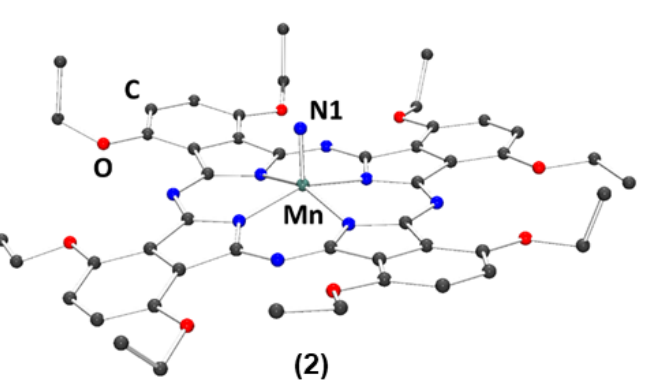

c)

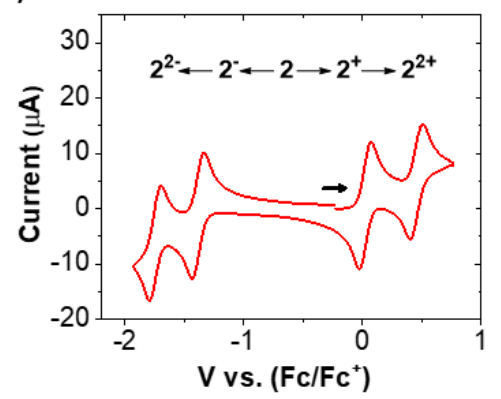

Figure 2. a) Synthesis of reported complexes following the general conditions: i) $\mathrm{MnCl}_{2}, \mathrm{DMF}, 100{ }^{\circ} \mathrm{C}, 5 \mathrm{~h}, \mathrm{O}_{2}$; ii) $\mathrm{NH} 4 \mathrm{OH} / \mathrm{NaOCl} \mathrm{MeOH}$, r.t., 15 mins; iii) $\left[\left(4-\mathrm{BrC}_{6} \mathrm{H}_{4}\right)_{3} \mathrm{~N}\right]\left[\mathrm{B}\left(\mathrm{C}_{6} \mathrm{~F}_{5}\right)_{4}\right]$ (2 eq.), DCM, r.t., 5 mins; iv) [(4- $\left.\left.\mathrm{BrC}_{6} \mathrm{H}_{4}\right)_{3} \mathrm{~N}\right]\left[\mathrm{B}\left(\mathrm{C}_{6} \mathrm{~F}_{5}\right)_{4}\right]$ (1 eq.), DCM, r.t., 5 mins; v) KC8 (1 eq.), kryp (1 eq.), THF, r.t., 10 mins; vi) $\mathrm{KC}_{8}$ (5 eq.), kryp (2 eq.), THF, r.t., 10 mins. b) Solid state molecular structure of 2 . $\mathrm{H}$ atoms and co-crystallized solvent have been omitted for clarity. c) $\mathrm{CV}$ of 2, taken in DCM. Conditions: $0.29 \mathrm{mM}$ of $2,0.1 \mathrm{M}$ of [Bu $\left.\mathrm{Bu}^{\mathrm{N}}\right]\left[\mathrm{PF}_{6}\right], 3 \mathrm{~mm}$ diameter glassy carbon working electrode, Pt wire counter electrode, and Pt wire pseudo-reference electrode.

Herein, we demonstrate what we credit as the first such clearly characterized example of a macrocyclic Pc complex that can readily access aromatic (neutral), anti-aromatic (di-reduced), and non-aromatic (di-oxidized) states, in addition to the singly oxidized or reduced states. This was accomplished using the new Mn-nitride, ( $\left.{ }^{\mathrm{OEt}} \mathrm{Pc}\right) \mathrm{MnN} \quad\left(\mathbf{2}, \quad{ }^{\mathrm{OEt}} \mathrm{Pc}=\right.$ $1,4,8,11,15,18,22,25$-octaethoxy-Pc), by chemical oxidation or reduction. The redox behavior and electronic structure were probed through a suite of structural, spectroscopic, electrochemical, and computational methods and revealed ligandborne redox events with the $\mathrm{Pc}$ ligand spanning from $\mathrm{Pc}(0)$ to Pc(4-) formal oxidation states. Additionally, compelling evidence for the operative local and macrocyclic resonance circuits are provided. We consider this complex a rare class of resonance circuit model compound due to the capability of accessing all three principal states of aromatic behavior in a stable and isolable manner, and apparent changing of resonance circuit pathways as a function of redox state. This study may provide valuable information on the interplay of redox state and aromatic character in Pc and related macrocycles, and may serve as an excellent platform in which to study molecular material applications pertaining to tunable aromaticity.

\section{RESULTS AND DISCUSSION}

Synthesis. The symmetrically substituted pro-ligand, ${ }^{\mathrm{E} t O} \mathrm{PcH}_{2}$, was prepared by previously reported methods. ${ }^{27-28}$ Metallation of ${ }^{\mathrm{EtO}} \mathrm{PcH}_{2}$ with $\mathrm{MnCl}_{2}$ under aerobic conditions in refluxing dimethyl formamide (DMF) for $5 \mathrm{~h}$ yielded a dark red product $\left(\lambda_{\max }=825 \mathrm{~nm}\right)$ after purification (Note: all $\lambda_{\max }$ values reported correspond to the $\mathrm{Q}$ peaks) (Figure $2 \mathrm{a}$, path i). ${ }^{29}$ Single crystals suitable for XRD studies were grown by layering benzene over a saturated fluorobenzene solution and confirmed the structure as the $\mathrm{Mn}(\mathrm{III})$ species, ${ }^{\mathrm{E} O} \mathrm{PcMnCl}$ (1) (Figure S26). Bond metrics are similar to other $\mathrm{Mn}(\mathrm{III}) \mathrm{Cl}$ macrocyclic species, such as a similar porphyrin derivative. ${ }^{30}$ The high-spin, $S=2$ state at Mn was confirmed by solution magnetic moment determination using the Evans method, ${ }^{31}$ and resulted in paramagnetically broadened resonances in the ${ }^{1} \mathrm{H}$ NMR spectrum.

Our interest in generating a terminal Mn-nitride stemmed from our previous work. ${ }^{32}$ The nitride, ${ }^{\mathrm{EtO}} \mathrm{PcMnN}$ (2), was readily generated from 1 under oxidative conditions using $\mathrm{NaOCl}$ and aqueous $\mathrm{NH}_{3}$ in methanol (Figure 2a, path ii). ${ }^{32-34}$ The dark green $\left(\lambda_{\max }=767 \mathrm{~nm}\right)$ diamagnetic complex was isolated in high yield $(\sim 89 \%)$ and was structurally characterized by XRD studies (Figure 2b). While several Pc metal nitrides have been reported, ${ }^{35-36}$ including with $\mathrm{Mn},{ }^{37-40} 2$ represents the first crystallographically characterized terminal Pc-metal nitride complex, according to the Cambridge Structural Database. The $\mathrm{Mn} \equiv \mathrm{N}$ in 2 is $1.555(9) \AA$, similar to other $\mathrm{Mn}=\mathrm{N}$ bonds in comparable symmetry and oxidation state..$^{34,41-42}$ A more detailed structural analysis is provided in the following section. The low-spin, diamagnetic nature of $\mathbf{2}$ is further consistent with other triply bonded $\mathrm{Mn}(\mathrm{V})$ nitrides, as is the $\mathrm{Mn} \equiv \mathrm{N}$ stretching frequency located at $1030 \mathrm{~cm}^{-1}$, identified by comparison with the isotopologue, $\mathbf{2 -}^{15} \mathbf{N}$ (Figures S19). ${ }^{32,43}$

Phthalocyanines are well-known redox-active ligands capable of spanning multiple oxidation states from $\operatorname{Pc}(0)$ to $\operatorname{Pc}(6-){ }^{29}$ In conjunction with a highly redox-active metal center $(\mathrm{Mn})$, we next proceeded to evaluate the redox behavior of 2 . Electrochemical analysis of 2 by cyclic voltammetry (CV) in dichloromethane (DCM) revealed a total of 4 reversible redox events (Figure 2c): 2 separate oxidation events at $E_{1 / 2}=0.02 \mathrm{~V}$ and $E_{1 / 2}$ $=0.45 \mathrm{~V}$, and 2 reduction events at $E_{1 / 2}=-1.38 \mathrm{~V}$ and $E_{1 / 2}$ $=-1.75 \mathrm{~V}$ referenced to the ferrocene/ferrocenium $\left(\mathrm{Fc} / \mathrm{Fc}^{+}\right)$redox couple. Given the aromatic nature of $\mathbf{2}$, as well as the relative scarcity of crystallographically-characterized PcM complexes in varying oxidation states, ${ }^{18,20-21,44-48}$ we next proceeded to isolate each redox state to gain an understanding of the changing aromaticity and concomitant structural changes.

The oxidized complexes were targeted using the tris(4-bromophenyl)ammoniumyl tetrakis(pentafluorophenyl)borate "magic blue" oxidant, [(4-BrC $\left.\left.{ }_{6} \mathrm{H}_{4}\right)_{3} \mathrm{~N}\right]\left[\mathrm{B}\left(\mathrm{C}_{6} \mathrm{~F}_{5}\right)_{4}\right]\left(E_{1 / 2}=0.70 \mathrm{~V}\right.$ vs. $\left.\mathrm{Fc} / \mathrm{Fc}^{+}\right) .{ }^{32,49-50}$ To isolate the mono-oxidized product, a dark green diamagnetic solution of $\mathbf{2}$ in DCM was treated to 1 equivalent of $\left[\left(4-\mathrm{BrC}_{6} \mathrm{H}_{4}\right)_{3} \mathrm{~N}\right]\left[\mathrm{B}\left(\mathrm{C}_{6} \mathrm{~F}_{5}\right)_{4}\right]$ resulting in a dark red $\left(\lambda_{\max }\right.$ $=820 \mathrm{~nm}$ ), ${ }^{1} \mathrm{H}$ NMR-silent solution (Figure $2 \mathrm{a}$, path iv). Single crystals suitable for XRD studies of the product were grown by layering benzene over a saturated fluorobenzene solution. The solid-state structure confirmed the composition of the new product as $\left[{ }^{\mathrm{EtO}} \mathrm{PcMnN}\right]\left[\mathrm{B}\left(\mathrm{C}_{6} \mathrm{~F}_{5}\right)_{4}\right]\left(\mathbf{2}^{+}\right)$(Figure $\mathrm{S} 29$ ). To probe the locus of oxidation in $\mathbf{2}^{+}$, single crystals were dissolved in DCM and analyzed by X-band EPR spectroscopy at $100 \mathrm{~K}$. An intense isotropic signal centered at $\mathrm{g}=1.995$ indicative of an 
organic radical species is observed, consistent with a $1 \mathrm{e}^{-}$oxidation of the ligand $\pi$ system (Figure S13). In contrast, treatment of 2 with 2 equivalents of $\left[\left(4-\mathrm{BrC}_{6} \mathrm{H}_{4}\right)_{3} \mathrm{~N}\right]\left[\mathrm{B}\left(\mathrm{C}_{6} \mathrm{~F}_{5}\right)_{4}\right]$ resulted in a deep fuchsia $\left(\lambda_{\max }=832 \mathrm{~nm}\right)$ solution which, after workup, displayed an upfield shifted diamagnetic ${ }^{1} \mathrm{H}$ NMR spectrum relative to $\mathbf{2}$ (vide infra) (Figure 2a, path iii). Single crystals suitable for XRD studies were isolated by layering a concentrated solution of product in fluorobenzene with benzene at room temperature. The identity of the product was confirmed as the di-cation, [ $\left.{ }^{\mathrm{EtO}} \mathrm{PcMnN}\right]\left[\mathrm{B}\left(\mathrm{C}_{6} \mathrm{~F}_{5}\right)_{4}\right]_{2}\left(\mathbf{2}^{2+}\right)$ (Figure $\mathrm{S} 30$ ). Structural characteristics for both $2^{+}$and $2^{2+}$ are described in more detail in the following section.

For the anionic states of $2, \mathrm{KC}_{8}$ was used as the reductant of choice. ${ }^{51}$ Chemical reduction of 2 with 1 equivalent of $\mathrm{KC}_{8}$ in the presence of the cryptand, 4,7,13,16,21,24-hexaoxa-1,10-diazabicyclo[8.8.8]hexacosane (Kryptofix-222 = kryp), resulted in a dark teal $\left(\lambda_{\max }=751 \mathrm{~nm}\right),{ }^{1} \mathrm{H}$ NMR silent solution. Single crystals suitable for XRD studies were grown from tetrahydrofuran (THF)/isooctane by vapor diffusion and the solid-state structure confirmed the composition as the mono-anion, [K(kryp) $]\left[{ }^{\mathrm{EtO}} \mathrm{PcMnN}\right]\left(\mathbf{2}^{-}\right)$(Figures 2a, path v, S27). Similar to $\mathbf{2}^{+}$, the EPR spectrum of $\mathbf{2}^{-}$dissolved in THF revealed an intense, isotropic signal centered at $\mathrm{g}=1.996$ consistent with a ligand-borne reduction event (Figure S15). Similarly, treatment of 2 with excess $\mathrm{KC}_{8}$ in the presence of Kryptofix-222 yielded a dark blue $\left(\lambda_{\max }=699 \mathrm{~nm}\right)$ diamagnetic complex which, similar to $\mathbf{2}^{\mathbf{2 +}}$, displays an upfield shifted ${ }^{1} \mathrm{H}$ NMR spectrum relative to 2 (vide infra). Single crystals suitable for XRD studies were grown from benzene/isooctane by vapor diffusion and the solidstate structure confirmed the composition as the di-anion, $[\mathrm{K}(\mathrm{kryp})]_{2}\left[{ }^{\mathrm{EtO}} \mathrm{PcMnN}\right]\left(\mathbf{2}^{\mathbf{2}}\right)$ (Figures 2a, path vi, S28). Structural characteristics for both $\mathbf{2}^{-}$and $\mathbf{2}^{\mathbf{2}}$ are described in more detail in the following section. We note that $\mathbf{2}^{\mathbf{2}-\text { likely contains }}$ trace $2^{-}$in solution as observed by a resonance in the EPR spectrum similar to 2- (Figure S16). This is a known issue with compounds containing the highly reduced $\mathrm{Pc}(4-)$ ligand $^{21}$ and likely accounts for a small amount of contamination in solution.

Structural Properties. While both metal and/or ligand-based redox events are possible in this system, a closer look at the $\mathrm{Mn} \equiv \mathrm{N}$ bond lengths for $\mathbf{2}^{\mathbf{2 +}} \rightarrow \mathbf{2}^{\mathbf{2}-}$ (Figure 3 ) suggests little to no participation of the Mn center in the observed redox processes, consistent with the EPR spectroscopic results above. Such participation would be expected to either render the $\mathrm{Mn} \equiv \mathrm{N}$ bond reactive ${ }^{32,52}$ and/or alter its bond length. In contrast, the observed bond lengths are all similar to other $\mathrm{Mn}(\mathrm{V}) \equiv \mathrm{N}$ bonds in comparable symmetry and oxidation states. ${ }^{32,34,41-43}$ The only notable change is with $\mathbf{2}^{\mathbf{2}-}$ where nitride coordination to a $\mathrm{K}^{+}$ (from $[\mathrm{K}(\mathrm{kryp})]^{+}$) occurs (Figure S28). However, this appears to have no impact on the $\mathrm{Mn} \equiv \mathrm{N}$ bond length (Figure 3 ) or the resulting diamagnetism of the compound. ${ }^{53}$

Perhaps the most striking differences between all structures are the pronounced Pc ring distortions. While PcM complexes generally adopt planar geometries, ${ }^{16,18,29,44,54}$ axial metal bonding (ex. $\mathrm{M}-\mathrm{Cl}, \mathrm{M}=\mathrm{O})^{20,44,46-47,55}$ and/or heavy element bonding in the pocket ${ }^{56-57}$ typically yields domed structures. In contrast, ortho group incorporation in the isoindole rings ${ }^{58-61}$ can result in saddling of the Pc ring with adjacent isoindole rings pointing in opposite directions relative to the $\mathrm{N}_{4}$ plane $\left(\mathrm{N}_{4}=\mathrm{N} 2-\mathrm{N} 4-\mathrm{N} 6-\right.$ N8, Figure 4a). ${ }^{60}$ The degree of doming or saddling is reported with respect

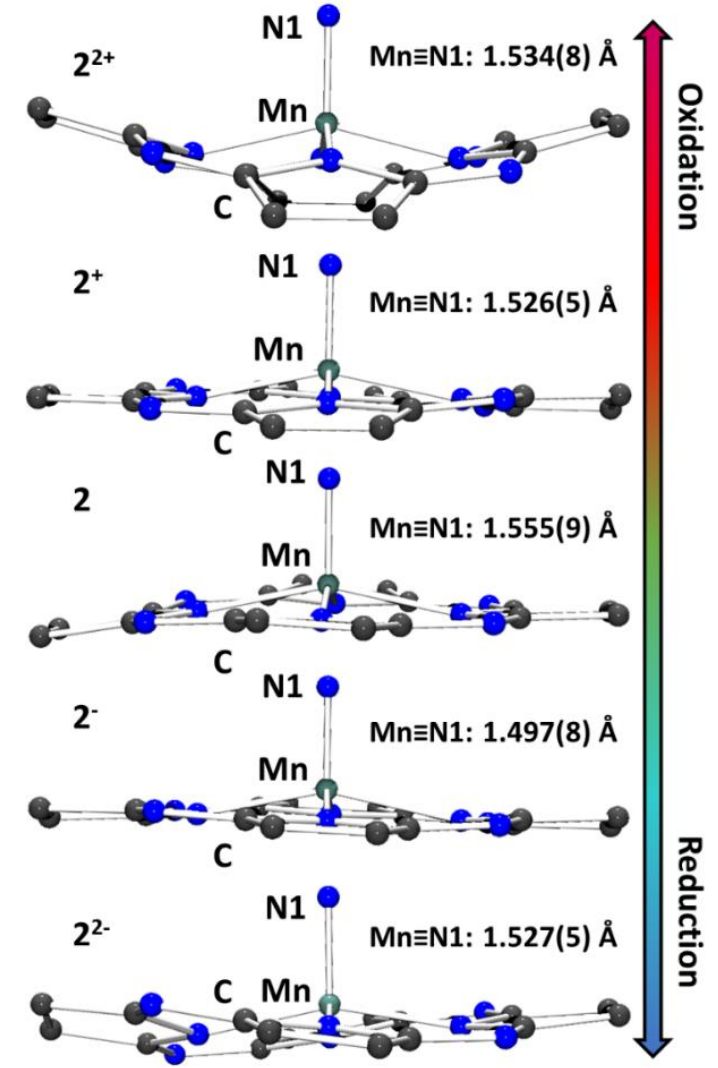

Figure 3. Solid-state structures of $\mathbf{2}^{2+}, \mathbf{2}^{+}, \mathbf{2}, \mathbf{2}$, and $\mathbf{2}^{2-}$ illustrating $\mathrm{Mn} \equiv \mathrm{N}$ bond lengths and core structural distortions. Hydrogen atoms, peripheral substituted benzene groups, and co-crystallized solvent molecules are omitted for clarity.

to the dihedral angles formed between the $\mathrm{N}_{4}$ and isoindole planes or between opposing isoindole planes (ex. $I_{l}$ vs. $I_{3}$, Figure 4a), respectively. ${ }^{20-21,58-61}$ While the $\mathrm{Mn} \equiv \mathrm{N}$ bond vector sits atop the $\mathrm{N}_{4}$ planes in our complexes (Figure 3) with $\mathrm{Mn}-\mathrm{N}_{4}$ distances ranging from $0.40-0.48 \AA$ (Table 1 ), none of the structures are domed. Only $\mathbf{2}^{\mathbf{2 +}}$ is saddled and contains dihedral angles of $27.7^{\circ}$ and $36.9^{\circ}$ (average $32.3^{\circ}$ ) for the $I_{1}-I_{3}$ and $I_{2}-I_{4}$ planes, respectively (Figure $4 \mathrm{a}$ ), comparable to very saddled structures. ${ }^{58}$ In contrast, $\mathbf{2}^{+}, \mathbf{2}, \mathbf{2}$, and $\mathbf{2}^{\mathbf{2}-}$ are best described as adopting mixed non-planar conformations. ${ }^{44}$ As such, we find that a description of each structure's distortions applying the domed/saddled dihedral convention is insufficient as each isoindole ring can be twisted and/or tilted relative to the $\mathrm{N}_{4}$ plane. Therefore, we define secondary $\gamma$ and $\delta$ planes encompassing the Mn-N1-N4-N8 and Mn-N1-N2-N6 planes, respectively. The twist/tilt angles are then calculated from the normal of an isoindole plane $\left(I_{i}\right)$ relative to a given $\gamma$ or $\delta$ plane (Table 1) with a clockwise twist or an upward tilt given as positive (Figure 4b). Using this approach provides a more detailed look at Pc ring distortions, while also capturing traditional saddled dihedral angles, such as for $2^{2+}$, by instead summing the $I_{1}-I_{3}$ and $I_{2}-I_{4}$ tilt angles (Table 1). As an overall metric of distortion, we have summed the average twist and tilt values and have found a clear trend in structural distortions wherein both $2^{2+}$ and $2^{2-}$ are heavily distorted $-19.0^{\circ}$ and $18.6^{\circ}$, respectively - relative to $\mathbf{2}^{+}$ $\left(6.9^{\circ}\right), 2\left(7.5^{\circ}\right)$, and $2^{-}\left(9.4^{\circ}\right)$ (Table 1$)$. 
Table 1. Tilt and twist dihedral angles for $2^{2+}, 2^{+}, 2,2^{-}$, and $2^{2-} \cdot{ }^{a}$

\begin{tabular}{|c|c|c|c|c|c|c|c|c|c|c|c|c|}
\hline & \multirow{2}{*}{$\begin{array}{c}\mathbf{M n}_{(\AA)} \mathbf{N}_{4} \\
\end{array}$} & \multicolumn{5}{|c|}{$\operatorname{twist}\left({ }^{\circ}\right)$} & \multicolumn{5}{|c|}{$\operatorname{tilt}\left({ }^{\circ}\right)$} & \multirow{2}{*}{$\begin{array}{c}\Sigma \\
\text { twist- } \\
\text { tilt }\end{array}$} \\
\hline & & $I_{1}-\delta$ & $I_{2}-\gamma$ & $I_{3}-\delta$ & $I_{4-\gamma}$ & |avg.| & $I_{1-\gamma}$ & $I_{2}-\delta$ & $I_{3}-\gamma$ & $I_{4}-\delta$ & |avg.| & \\
\hline $2^{2+}$ & 0.48 & -1.8 & -4.6 & -1.8 & -4.6 & 3.2 & -18.4 & 13.1 & -18.4 & 13.1 & 15.8 & 19.0 \\
\hline $2^{+}$ & 0.42 & 9.7 & -4.6 & -0.3 & 0.1 & 3.7 & -2.7 & 4.0 & 0.1 & -5.8 & 3.2 & 6.9 \\
\hline $2^{b}$ & $\begin{array}{c}0.40 \\
(0.41)\end{array}$ & $3.2(1.1)$ & $3.0(1.0)$ & $\begin{array}{c}-3.8 \\
(-5.6)\end{array}$ & $0.4(-0.2)$ & 2.3 & $5.2(2.6)$ & $1.4(1.9)$ & $5.7(4.6)$ & $\begin{array}{l}-11.7 \\
(-8.7)\end{array}$ & 5.2 & 7.5 \\
\hline $2^{-b}$ & $\begin{array}{c}0.41 \\
(0.45)\end{array}$ & $-6.0(6.9)$ & $-4.1(1.7)$ & $-6.0(6.9)$ & $-4.1(1.7)$ & 4.7 & $\begin{array}{c}-2.1(- \\
13.1)\end{array}$ & $-2.6(0.9)$ & $\begin{array}{c}-2.1 \\
(-13.1)\end{array}$ & $-2.6(0.9)$ & 4.7 & 9.4 \\
\hline $2^{2-}$ & 0.45 & 11.8 & -5.0 & 8.2 & -11.2 & 9.0 & -11.4 & -5.0 & 11.3 & -10.8 & 9.6 & 18.6 \\
\hline
\end{tabular}

${ }^{\text {a }}$ calculated from the normal of an isoindole plane $\left(I_{i}\right)$ relative to the $\gamma$ or $\delta$ plane where a clockwise twist or an upward tilt are given as positive (Figure $4 b$ ).

${ }^{\mathrm{b}}$ values in parentheses are from a second molecule in the asymmetric unit of the solid-state structure. Averages are taken of all values.

a)

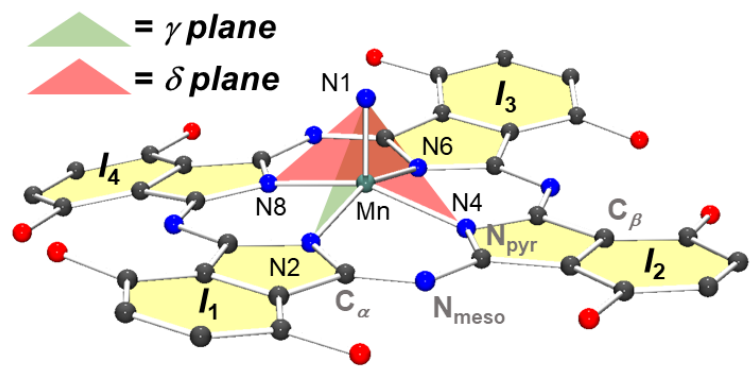

b)
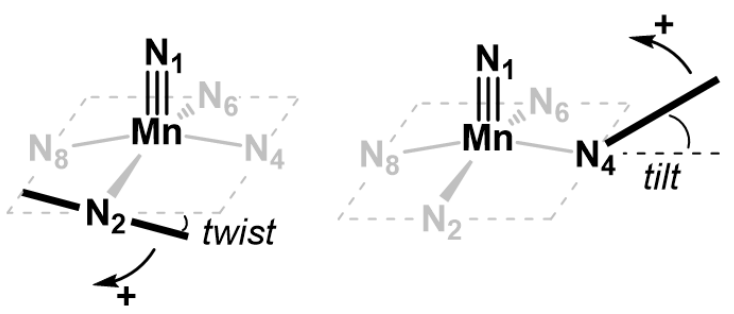

Figure 4. a) Depictions of the $\gamma, \delta$, and isoindolic $\left(I_{1}-I_{4}\right)$ planes, as well as relevant atom labels. b) Twist and tilt notation used in this report where clockwise twist and upward tilt are given positive values.

A closer look at the bond lengths within the ${ }^{\text {EtO }} \mathrm{Pc}$ structures may provide insight as to the nature of the distortions. While the $\mathrm{Pc}(2-)$ ligand is overall aromatic, this aromaticity is often ascribed to localized internal neutral [18] annulene or dianionic ([16]annulene $)^{2-} 18 \pi \mathrm{e}^{-}$circuits encircling the central pocket, as described above (Figure 1b-c). ${ }^{5,7,18,20-21}$ Assuming average C$\mathrm{N}$ single and double bond lengths of $1.47 \AA$ and $1.27 \AA{ }^{62}$ respectively, a closer look at the bond lengths in 2 suggests a [16]annulene circuit is at play (Figures 1c, S32A). Specifically, the average $\mathrm{C}-\mathrm{N}$ bond length of the [16]annulene $\left(\mathrm{C}_{8} \mathrm{~N}_{8}\right)$ circuit between pyrrolic nitrogen $\left(\mathrm{N}_{\mathrm{pyr}}\right)$ and $\mathrm{C}_{\alpha}$, as well as between meso nitrogen $\left(\mathrm{N}_{\text {meso }}\right)$ and $\mathrm{C}_{\alpha}$ (Figure $4 \mathrm{a}$ ) is $1.351 \AA$ (range: 1.307-1.408 $\AA$ ). In contrast, the average $\mathrm{C}_{\alpha}-\mathrm{C}_{\beta}$ bond length is $1.459 \AA$ (range: $1.436-1.473 \AA$ ), suggesting a disconnection between the central $\mathrm{C}_{8} \mathrm{~N}_{8}, 18 \pi \mathrm{e}^{-}$circuit from each of the outer 6 $\pi$ phenyl aromatic systems (Figure 1). Furthermore, the $\mathrm{C}_{8} \mathrm{~N}_{8}$ ring is nearly perfectly planar with an average atom-to-plane displacement of only $0.032 \AA$ (range: 0.002-0.095 ^) (Figure $\mathrm{S} 31)$. Together, this is consistent with a ([16]annulene $)^{2-}, 18 \pi \mathrm{e}$ model in $\mathbf{2}$ (Figure 1c). 5,7

Similar to $\mathbf{2}$, the average $\mathrm{C}_{\alpha}-\mathrm{C}_{\beta}$ bonds in $\mathbf{2}^{\mathbf{2 +}}$ are elongated (average: $1.444 \AA$; range: $1.434-1.454 \AA$ ) relative to the $\mathrm{C}-\mathrm{N}$ bonds of the $\mathrm{C}_{8} \mathrm{~N}_{8}$ core (average: $1.344 \AA$; range: $1.294-1.380$ $\AA$ ). This again suggests disconnected $6 \pi$ phenyl aromatic fragments tethered to a $16 \pi$ non-aromatic $\mathrm{C}_{8} \mathrm{~N}_{8}$ core (vide infra). In contrast to 2 , the change to a non-aromatic system in $\mathbf{2}^{\mathbf{2 +}}$ is evidenced by the significant distortions from planarity observed in the $\mathrm{C}_{8} \mathrm{~N}_{8}$ core where the average atom-to-plane displacement is now $0.145 \AA$ (range: 0.006-0.296 $\AA$ ) (Figure S31). Such reported $16 \pi$ non-aromatic porphyrinoid cores show similar degrees of distortions from planarity. ${ }^{22}$

A similarly distorted $\mathrm{C}_{8} \mathrm{~N}_{8}$ core is observed in $\mathbf{2}^{2-}$ where the average atom-to-plane displacement is slightly higher than $\mathbf{2}^{\mathbf{2 +}}$ at $0.159 \AA$ (range: 0.007-0.322 $\AA$ ) (Figure S31). However, in contrast to 2 and $\mathbf{2}^{2+}$, the $\mathrm{N}_{\text {meso }}-\mathrm{C}_{\alpha}$ bonds (Figure 4a) display a distinct short/long pattern with mean short and long bonds of $1.298 \AA$ (range: $1.295-1.301 \AA$ ) and $1.374 \AA$ (range: 1.370 $1.377 \AA$ ), respectively (Figure S32A). Furthermore, this short/long pattern propagates along a single axis containing two trans-disposed isoindole units, connected to the $\mathrm{C}_{8} \mathrm{~N}_{8}$ core by shortened $\mathrm{C}_{\alpha}-\mathrm{C}_{\beta}$ bonds (mean: $1.412 \AA$; range: $1.397-1.426 \AA$ ) relative to the perpendicular $\mathrm{C}_{\alpha}-\mathrm{C}_{\beta}$ set (mean: $1.467 \AA$; range: 1.460-1.474 $\AA$ ), the latter being similar to those in $\mathbf{2}$ and $\mathbf{2}^{\mathbf{2 +}}$. Together, this data suggests a $20 \pi \mathrm{e}^{-}$, dianionic ([18]annulene) $)^{2-}$ anti-aromatic framework (Figure 1b). The bond length patterns are also similar to previously observed anti-aromatic Pc(4-) systems. ${ }^{18,20-21}$

In contrast to the redox extrema in $\mathbf{2}^{\mathbf{2 +}}$ and $\mathbf{2}^{\mathbf{2 -}}, \mathbf{2}^{\mathbf{+}}$ and $\mathbf{2}^{-}$show minimal net distortions relative to $\mathbf{2}$ (Table 1), consistent with a delocalized radical state. The average $C_{\alpha}-C_{\beta}$ bond length for $2^{+}$ and $\mathbf{2}^{-}$do not vary significantly from the values of $\mathbf{2}$ (Figure $\mathrm{S} 32 \mathrm{~B})$. Additionally, the $\mathrm{M} \equiv \mathrm{N}$ bond length in both $2^{+}$(1.526(5) $\AA$ ) and 2- $(1.497(8) \AA$ ) relative to 2 (1.555(9) $\AA$ ) seem to suggest little electronic participation of the metal or apical nitrogen towards these events, corroborating the solution-state spectra that suggest a highly delocalized radical residing on the ring, a common state for mono-oxidized and mono-reduced macrocyclic systems. $^{16,30,45-47}$ 
Spectroscopic Properties. NMR spectroscopy is one of the most direct experimental methods for distinguishing diatropic from paratropic ring currents commonly associated with classic Hückel aromatic $(4 n+2) \pi$ and anti-aromatic $(4 n) \pi$ systems, respectively. ${ }^{1,63-65}$ Diatropic $\pi$ electron ring currents result in typical downfield shifted outer ring protons (ex. benzene), whereas an opposite paratropic current emerges in anti-aromatic systems resulting in an opposite upfield shift of outer ring protons. ${ }^{17-19}$, 66-67 The ${ }^{1} \mathrm{H}$ NMR resonances of 2 appear at $7.63(\mathrm{CH}), 4.97$ $\left(\mathrm{CH}_{2}\right)$, and $1.85\left(\mathrm{CH}_{3}\right)$ ppm in $\mathrm{CD}_{2} \mathrm{Cl}_{2}$ (Figure 5a). The corresponding resonances for $\mathbf{2}^{2+}$ in the same solvent are only slightly upfield shifted $(7.51,4.60$, and $1.60 \mathrm{ppm})$ and not indicative of any major paratropic ring current supporting a localized inner, non-aromatic [16] annulene ring (Figure 5b). In contrast, the resonances of $2^{2-}$ are significantly upfield shifted $(4.53,2.53$,

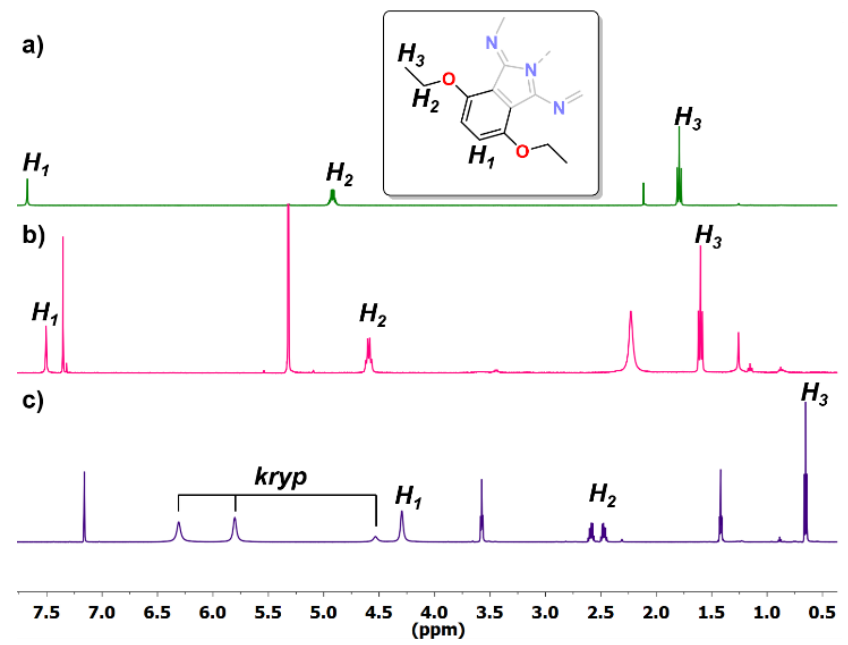

Figure 5. ${ }^{1} \mathrm{H}$ NMR spectra of a) 2 in $\mathrm{CD}_{2} \mathrm{Cl}_{2}$; b) $\mathbf{2}^{\mathbf{2 +}}$ in $\mathrm{CD}_{2} \mathrm{Cl}_{2}$; c) $\mathbf{2}^{2-}$ in $\mathrm{C}_{6} \mathrm{D}_{6}$, illustrating the shift in phenyl $\left(\mathrm{H}_{1}\right)$, methylene $\left(\mathrm{H}_{2}\right)$, and methyl $\left(\mathrm{H}_{3}\right)$ resonances as a function of oxidation state and associated aromatic character. Kryptofix-222 (kryp) resonances are also shown in c). Other peaks in a-c correspond to residual solvents.

$0.64 \mathrm{ppm}$ ) and indicative of a strong, inner paratropic current. In addition, the resonances attributed to the Kryptofix-222 protons are broadened and significantly downfield shifted at (6.30, $5.79,4.29 \mathrm{ppm}$ ) relative to published values (Figure $5 \mathrm{c}) .^{68-70}$ This may be the result of equilibrium coordination to the terminal nitride forcing the $[\mathrm{K}(\mathrm{kryp})]^{+}$cations to reside above the plane of the paratropic current, as observed in the solid state structure (Figure S28), and resulting in a downfield shift similar to previous reports. ${ }^{17-19,71}$ We note that the spectrum of $\mathbf{2}^{\mathbf{2 -}}$ was collected in $\mathrm{C}_{6} \mathrm{D}_{6}$ for stability reasons; however, this should have little impact on the observed drastic shift changes.

The UV-Vis spectra of all five isolated redox states in the series were measured. The Q-band for 2 occurs at $767 \mathrm{~nm}$ (Figure S21) and becomes progressively red-shifted and broadened upon oxidation $\left(\mathbf{2}^{+}\right.$: $820 \mathrm{~nm}, \mathbf{2}^{\mathbf{2 +}} 832 \mathrm{~nm}$; Figures S22-S23). Upon reduction, the Q-band is initially blue-shifted $(2: 751 \mathrm{~nm}$; Figure S24), and then splits into two discrete absorptions upon further reduction to $\mathbf{2}^{\mathbf{2}-}(699 \mathrm{~nm}, 767 \mathrm{~nm}$; Figure S25). These results do not follow predictive models proposed by Gouterman and Lever for the correlation between oxidation state and Qband position in metallophthalocyanines. ${ }^{72}$ However, it should be noted that due to the apparent switching of resonance circuits described in this report, and the high degree of structural distortions as a function of oxidation state (vide supra), it is difficult to draw concrete conclusions from the electronic spectra. Lastly, it should be noted that the UV-Vis spectrum of $\mathbf{2}^{\mathbf{2 +}}$ still displays striking low energy transitions for our non-aromatic assignment, differing from analogous $16 \pi \mathrm{e}^{-}$porphyrin-based systems. However, non-aromatic Pc-derivatives have been demonstrated to display such UV-Vis spectra, and may be the result of intra-macrocycle charge transfer transitions. ${ }^{73}$

Computational Results. To correlate our NMR data, we performed Nucleus-Independent Chemical Shift (NICS) calculations on $\mathbf{2}, \mathbf{2}^{\mathbf{2 +}}$, and $\mathbf{2}^{\mathbf{2}-}$ (Figure 6 a-c). Developed by Schleyer, ${ }^{74}$ this technique has been highly effective in distinguishing diatropic (aromatic) from paratropic (anti-aromatic) ring currents in macrocyclic compounds, such as porphyrinoids and Pc. ${ }^{2,9,17-}$ 18, 25, 63, 75 The NICS calculations were performed at a point in space $1 \AA$ above the plane of each sub-ring following the normal (see Figure 6a blue dots which indicate the centers of each sub-ring). For $\mathbf{2}$, negative NICS values are observed throughout the entire ring system (Figure 6a), consistent with diatropic (aromatic) current. In contrast, a substantial reduction in diatropic current is observed in $2^{2+}$, particularly in the central [16]annulene core and adjacent pyrrole sub-rings, indicating a significant decrease in aromaticity (Figure 6b). The outer phenyl fragments, however, are significantly less affected by this loss in diatropic current, supporting a localized aromaticity switch from aromatic (2) to non-aromatic $\left(2^{2+}\right)$ at the [16]annulene core. These NICS data are also consistent with the observed modest upfield shift of the ${ }^{1} \mathrm{H}$ NMR resonances for $\mathbf{2}^{2+}$ relative to 2 (Figure 5a-b). Together, we propose that the switch from aromatic (2) to non-aromatic $\left(2^{2+}\right) \pi$ systems is likely the root cause of the significant structural distortions observed in $2^{2+}$ relative to 2 (Figure 3, Table 1), with the former adopting a central [16]annulene $16 \pi \mathrm{e}^{-}$core. Indeed, structural parameters, such as atom-to-plane displacement patterns (vide supra, Figure $\mathrm{S} 31$ ), largely mimic those reported for the solid state structure of authentic [16]annulene. ${ }^{76}$

More drastic changes are observed in the high positive NICS values of $\mathbf{2}^{\mathbf{2}-}$ relative to $\mathbf{2}$, consistent with a strong paratropic ring current extending along a dianionic ([18]annulene) ${ }^{2-} 20 \pi$ $\mathrm{e}^{-}$antiaromatic core (Figure $6 \mathrm{c}$ ). These NICS data are consistent with the large upfield shifts observed for peripheral Pc protons, and downfield shifts observed for Kryptofix-222 protons sitting atop the paratropic ring current (vide supra, Figure $5 \mathrm{c}$ ). This paratropic circuit, spanning a single [18]annulene axis, is also supported by the structural data indicating short vs. long $\mathrm{C}_{\alpha}-\mathrm{C}_{\beta}$ bond lengths in orthogonal isoindole units (vide supra and Figure $6 c$ ). As in $\mathbf{2}^{2+}$, we believe that the aromaticity switch between $\mathbf{2}$ (aromatic) and $\mathbf{2}^{\mathbf{2}-}$ (antiaromatic) is mostly responsible for the significant structural distortions observed (vide supra, Figure 3, Table 1), similar to those observed from planar $[18]$ annulene ${ }^{77}$ to the distorted ([18]annulene) $)^{2-}$ dianion. $^{78}$

DFT studies at the M06-2X level of theory with the 6$31+\mathrm{G}^{* *}$ basis set were also performed on the entire isostructural series $\mathbf{2}^{2+}, \mathbf{2}^{+}, \mathbf{2}, \mathbf{2}$, and $\mathbf{2}^{\mathbf{2}}$, utilizing the XRD coordinates as starting geometries (see SI for full computational details). The highest occupied molecular orbitals (HOMOs) for $\mathbf{2}, \mathbf{2}^{\mathbf{2 +}}$, and $\mathbf{2}^{2-}$ are shown in Figures 6d, 6e, and 6f, respectively. 
a)

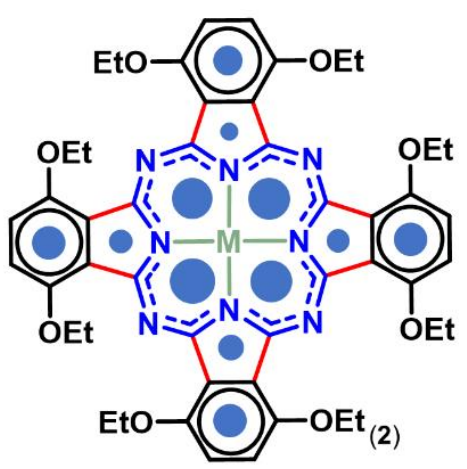

d)

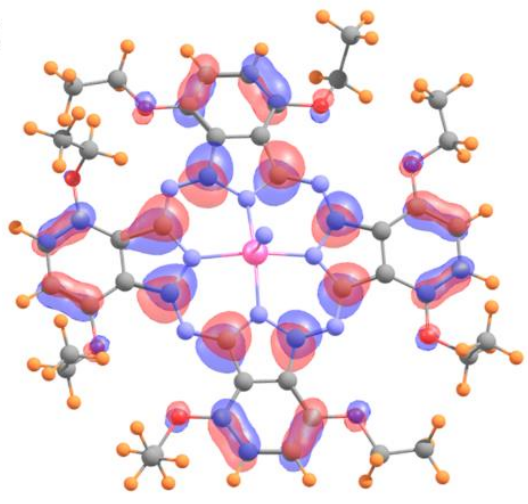

b)

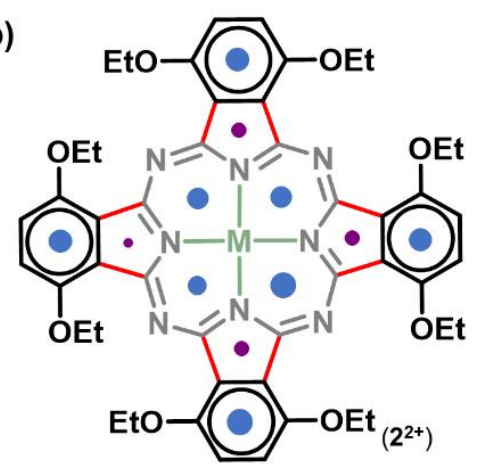

e)

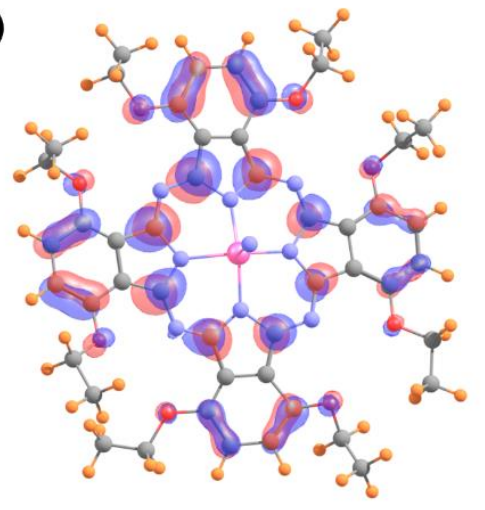

c)

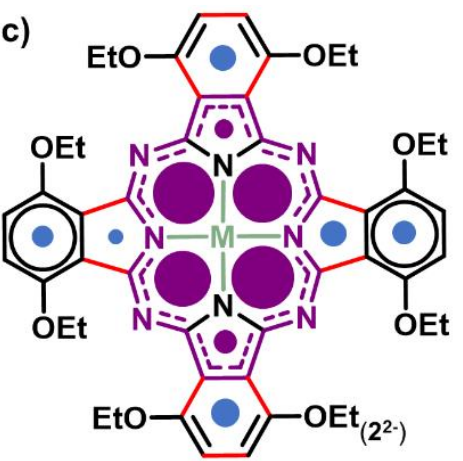

f)

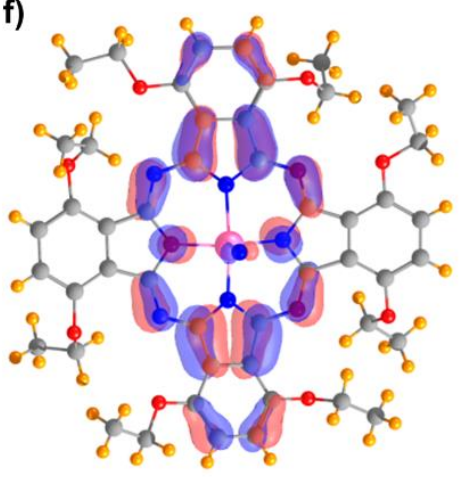

Figure 6. (a-c) Proposed aromatic (blue), non-aromatic (gray), and anti-aromatic (purple) circuits, as well as elongated single bonds (red) for 2 (a), $\mathbf{2}^{2+}$ (b), $\mathbf{2}^{2-}$ (c). Circles represent NICS values, with the area of each circle directly proportional to the NICS value (blue=negative, purple=positive), at $1 \AA$ above the respective sub-ring geometric center and normalized against the highest absolute value (see SI for full computational details). (d-f) Corresponding HOMOs for 2 (d), $\mathbf{2}^{2+}(\mathrm{e}), \mathbf{2}^{\mathbf{2}-}$ (f).

For $\mathbf{2}$ and $\mathbf{2}^{\mathbf{2}}$, a central spin density contribution encompassing the proposed [16]annulene core, encircled by a circular node, is observed and is flanked by spin densities on the outer benzene fragments (Figures 6a-b,d-e). Interestingly, the HOMO of $\mathbf{2}^{\mathbf{2}-}$ also reflects the structural data and model proposed for the antiaromatic [18]annulene model (Figures 6c,f). The spin density shown also corresponds to the short bonds described above. Together, the frontier orbitals of all complexes are consistent with exclusively ligand-borne redox events with little to no contribution from the Mn center (Figures S40-S44). The only exception is in $\mathbf{2}^{\mathbf{2}}$ where the HOMO displays a small fraction of spin density at the nitride, consistent with its coordination to $[\mathrm{K}(\mathrm{kryp})]^{+}$

(Figures 6f, S28).

\section{CONCLUSION}

In conclusion, we have outlined the synthesis and characterization of a novel manganese nitride phthalocyanine (2), which is the first clearly characterized example of a large macrocyclic system that can access the triad of aromatic, non-aromatic, and antiaromatic states through a series of reversible redox events. Combined structural, spectroscopic, and computational studies reveal that all redox events are ligand-borne centering on specific annulene-like internal circuits. Altering the degree of aromaticity and pathway of these circuits is proposed to be the root cause of the observed structural distortions. Perhaps surprisingly, the frontier orbitals are demonstrated to have minimal contribution from the $\mathrm{Mn}(\mathrm{V})$ center or the apical nitrogen. The synthetic accessibility, stability, isolable nature, and scope of aromatic behavior make this complex an attractive platform for studying switchable aromaticity in broader contexts, such as in organic electronic devices. Our current interests are in studying these stable complexes as charge carriers for energy storage applications.

\section{EXPERIMENTAL SECTION}

3,6-Diethoxyphthalonitrile. 3,6-Diethoxyphthalonitrile was synthesized using a modified procedure previously reported by Rauchfuss. ${ }^{28}$ A mixture of $10.00 \mathrm{~g}$ (0.062 mol, 1 eq.) of 2,3dicyanohydroquinone and $17.26 \mathrm{~g}$ ( $0.124 \mathrm{~mol}, 2$ eq. $)$ of $\mathrm{K}_{2} \mathrm{CO}_{3}$ in $125 \mathrm{~mL}$ of wet acetone was heated to reflux and sparged with $\mathrm{N}_{2}$ for 10 mins. Ethyl iodide (29.02 g, 0.186 mol, 3 eq.) was then added dropwise to the mixture. The yellow slurry was stirred under reflux for $24 \mathrm{~h}$. After cooling, the yellow solid was filtered off and washed with $500 \mathrm{~mL}$ of water, $150 \mathrm{~mL}$ of $\mathrm{Et}_{2} \mathrm{O}$, collected, and then dried under vacuum to afford an off-white powder. Yield: $6.78 \mathrm{~g}(50.2 \%) .{ }^{1} \mathrm{H} \mathrm{NMR}\left(400 \mathrm{MHz}, \mathrm{CDCl}_{3}\right)$ : $\delta$ $7.14\left(\mathrm{~s}, 2 \mathrm{H}, \mathrm{C}_{6} \mathrm{H}_{2}\right.$.), 4.13 (q, J = 7.0 Hz, 4H, OCH $\left.\mathrm{CH}_{3}\right), 1.47$ (t, $\left.J=7.0 \mathrm{~Hz}, 6 \mathrm{H}, \mathrm{OCH}_{2} \mathrm{CH}_{3}\right)$.

Lithium 1,4,8,11,15,18,22,25-Octaethoxyphthalocyanine $\left({ }^{\text {Eto }} \mathbf{P c H L i}\right)$. This precursor was synthesized using a modified procedure previously reported by Rauchfuss. ${ }^{28} \mathrm{~A}$ mixture of

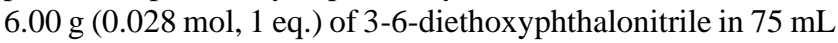
of wet EtOH was heated to reflux and sparged with $\mathrm{N}_{2}$ for 10 mins. Li pellets (2.43 g, $0.347 \mathrm{~mol}, 12.5 \mathrm{eq}$.) were added over the course of 10 mins, resulting in a large quantity of white gas evolving as the mixture turned dark green. After addition of the Li pellets, another $75 \mathrm{~mL}$ of wet $\mathrm{EtOH}$ was added. The mixture 
was refluxed for 5 days. After cooling, $100 \mathrm{~mL}$ of EtOH and $100 \mathrm{~mL}$ of $\mathrm{H}_{2} \mathrm{O}$ was added and the green solid was filtered off and washed with $100 \mathrm{~mL}$ of $\mathrm{H}_{2} \mathrm{O}, 100 \mathrm{~mL}$ of $\mathrm{EtOH}$, and 100 $\mathrm{mL}$ of $\mathrm{Et}_{2} \mathrm{O}$. The resulting green powder was dried under dynamic vacuum for $24 \mathrm{~h}$. Yield: $4.64 \mathrm{~g}(76.6 \%)$. ${ }^{1} \mathrm{H}$ NMR (400 $\left.\mathrm{MHz}, \mathrm{CDCl}_{3}\right): \delta 14.74(\mathrm{~s}, 1 \mathrm{H}, \mathrm{NH}), 7.52-7.42\left(\mathrm{~m}, 8 \mathrm{H}, \mathrm{C}_{6} \mathrm{H}_{2}\right)$, $4.95\left(\mathrm{~m}, 16 \mathrm{H}, \mathrm{OCH}_{2} \mathrm{CH}_{3}\right), 1.82\left(\mathrm{~m}, 24 \mathrm{H}, \mathrm{OCH}_{2} \mathrm{CH}_{3}\right) .{ }^{7} \mathrm{Li} \mathrm{NMR}$ $\left(\mathrm{CDCl}_{3}\right)$ : Silent.

1,4,8,11,15,18,22,25-Octaethoxyphthalocyanine $\quad\left({ }^{\mathrm{EtO}} \mathrm{PcH}_{2}\right)$.

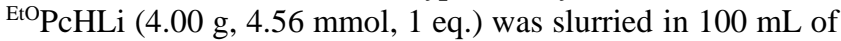
$\mathrm{H}_{2} \mathrm{O}$ in a flask and heated to $60{ }^{\circ} \mathrm{C}$. $\mathrm{HCl}(12.1 \mathrm{M}, 4 \mathrm{~mL}, 10$ eq. $)$ was added dropwise over the course of 15 mins, changing the green slurry to a purple solution. After $72 \mathrm{~h}$ of stirring, $19 \mathrm{~g}$ ( $0.1368 \mathrm{~mol}, 30$ eq.) of $\mathrm{K}_{2} \mathrm{CO}_{3}$ was carefully added over the course of $15 \mathrm{mins}$, returning the purple solution to a green slurry. The slurry was filtered, and washed with $100 \mathrm{~mL}$ of $\mathrm{H}_{2} \mathrm{O}$, and $100 \mathrm{~mL}$ of $\mathrm{Et}_{2} \mathrm{O}$. The resulting green powder was dried under vacuum. Yield: $2.81 \mathrm{~g}(71 \%)$. ${ }^{1} \mathrm{H}$ NMR (400 MHz, $\left.\mathrm{CDCl}_{3}\right)$ : $\delta 7.61\left(\mathrm{~s}, 8 \mathrm{H}, \mathrm{C}_{6} \mathrm{H}_{2}\right), 4.95\left(\mathrm{q}, J=7.0 \mathrm{~Hz}, 16 \mathrm{H}, \mathrm{OCH}_{2} \mathrm{CH}_{3}\right), 1.84$ (t, $\left.J=7.0 \mathrm{~Hz}, 24 \mathrm{H}, \mathrm{OCH}_{2} \mathrm{CH}_{3}\right), 0.21(\mathrm{~s}, 2 \mathrm{H}, \mathrm{NH})$.

${ }^{\text {Eto }} \mathrm{PcMnCl}$ (1). A mixture of $2.00 \mathrm{~g}$ (2.3 mmol, 1 eq.) of ${ }^{\mathrm{EtO}} \mathrm{PcH}_{2}, 2.00 \mathrm{~g}$ (excess) of $\mathrm{MnCl}_{2}$, and $0.969 \mathrm{~g}$ (11.5 mmol, 5 eq.) of $\mathrm{NaHCO}_{3}$ was slurried in $20 \mathrm{~mL}$ DMF in open air and heated to $100{ }^{\circ} \mathrm{C}$ for $5 \mathrm{~h}$, resulting in a red/purple solution. After cooling, $150 \mathrm{~mL}$ of water was added, and the solution was stirred for 30 mins. The mixture was filtered, and washed with $100 \mathrm{~mL}$ of water, followed by $100 \mathrm{~mL}$ of $\mathrm{Et}_{2} \mathrm{O}$. The resulting red powder was dried under vacuum. Single crystals suitable for XRD studies were obtained by layering benzene over a saturated fluorobenzene solution of $\mathbf{1}$ at room temperature. Yield: $1.35 \mathrm{~g}(61.4 \%)$. ${ }^{1} \mathrm{H}$ NMR (400 MHz, $\mathrm{CD}_{2} \mathrm{Cl}_{2}$ ): $\delta 6.69$ (bs), 1.74 (bs), -5.82 (bs). Anal. Calc. for $\mathrm{C}_{48} \mathrm{H}_{48} \mathrm{ClMnN}_{8} \mathrm{O}_{8} \cdot \mathrm{CH}_{2} \mathrm{Cl}_{2}$ : C, 56.58; H, 4.84; N, 10.77. Found: C, 55.66; H, 4.47; N, 11.73. $\mu_{\text {eff }}($ Evans method $): 4.64 \mu_{B}(S=2)$. $\lambda_{\max }(\mathrm{Q}$-peak $)=825 \mathrm{~nm}$.

${ }^{E t O} P \boldsymbol{C M n N}$ (2). Compound 1 (1.05 g, $1.05 \mathrm{mmol}, 1$ eq.) was added to $100 \mathrm{~mL}$ of $\mathrm{MeOH}$, resulting in a purple/red solution. Concentrated $\mathrm{NH}_{4} \mathrm{OH}$ (1.05 mL, 14.7 mmol, 15 eq.) was added dropwise over the course of 5 mins followed by $9.5 \mathrm{~mL}$ ( 6 eq.) Clorox ${ }^{\circledR}$ bleach over the course of 15 mins, resulting in the production of a white gas and a green solution. The solution was stirred for an additional 5 mins and then placed into an ice bath for 10 mins. While cooling, $75 \mathrm{~mL}$ of DCM was slowly added, followed by $50 \mathrm{~mL}$ of $\mathrm{H}_{2} \mathrm{O}$, and subsequently transferred to a separatory funnel. The organic layer was washed 3 times with $50 \mathrm{~mL}$ of $\mathrm{H}_{2} \mathrm{O}$ and then reduced to dryness under vacuum at 60 ${ }^{\circ} \mathrm{C}$, yielding a dark green powder which was then dissolved in DCM and recrystallized by layering with $\mathrm{Et}_{2} \mathrm{O}$, yielding dark green plate-like crystals. Yield: $0.908 \mathrm{~g}(88.5 \%)$. ${ }^{1} \mathrm{H}$ NMR $(400$ $\mathrm{MHz}, \mathrm{CD}_{2} \mathrm{Cl}_{2}$ ): $\delta 7.63\left(\mathrm{~s}, 8 \mathrm{H}, \mathrm{C}_{6} \mathrm{H}_{2}\right), 4.97\left(\mathrm{~m}, 16 \mathrm{H}, \mathrm{OCH}_{2} \mathrm{CH}_{3}\right)$, $1.85\left(\mathrm{t}, J=7.0 \mathrm{~Hz}, 24 \mathrm{H}, \mathrm{OCH}_{2} \mathrm{CH}_{3}\right) .{ }^{13} \mathrm{C}\left\{{ }^{1} \mathrm{H}\right\} \mathrm{NMR}: \delta 150.9$, 148.3, 127.2, 117.6, 67.0, 15.44. Anal. Calc. for $\mathrm{C}_{48} \mathrm{H}_{48} \mathrm{MnN}_{9} \mathrm{O}_{8}$ : C, 61.73; H, 5.18; N, 13.50. Found: C, 61.59; $\mathrm{H}, 5.00 ; \mathrm{N}, 13.45 . \lambda_{\max }(\mathrm{Q}-$ peak $)=767 \mathrm{~nm}$.

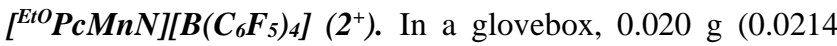
$\mathrm{mmol}$ ) of 2 was dissolved in $\sim 7.5 \mathrm{~mL}$ of DCM. [(4$\left.\left.\mathrm{BrC}_{6} \mathrm{H}_{4}\right)_{3} \mathrm{~N}\right]\left[\mathrm{B}\left(\mathrm{C}_{6} \mathrm{~F}_{5}\right)_{4}\right](24.9 \mathrm{mg}, 0.0214 \mathrm{mmol}, 1$ eq.) was dissolved in $\sim 2.5 \mathrm{~mL}$ of DCM, which was added dropwise to the green DCM solution of $\mathbf{2}$ under stirring, turning the solution wine red. The solution was stirred for 5 mins, then reduced to dryness under reduced pressure. Benzene $(15 \mathrm{~mL})$ was added, and the solution was stirred for an additional 10 mins. The slurry was filtered through a glass wool Celite ${ }^{\circledR}$ plug resulting in a light green/yellow effluent and dark powder on the plug. The powder was extracted with DCM, resulting in a wine-red solution. The solution was pumped to dryness, resulting in a dark red powder that was stored at $-40{ }^{\circ} \mathrm{C}$. Recrystallizations were performed by layering in fluorobenzene with benzene at room temperature, resulting in small trapezoidal red crystals. Yield: $0.031 \mathrm{~g}(90.9 \%)$. ${ }^{1} \mathrm{H}$ NMR (400 MHz, $\mathrm{CD}_{2} \mathrm{Cl}_{2}$ ): Silent. ${ }^{11} \mathrm{~B}\left\{{ }^{1} \mathrm{H}\right\}$ NMR: $\delta$-14.7 (s). ${ }^{19} \mathrm{~F}\left\{{ }^{1} \mathrm{H}\right\}$ NMR: $\delta 131.2(\mathrm{bs}), 161.8$ (t), 165.6 (bs). Anal. Calc. for $\mathrm{C}_{72} \mathrm{H}_{48} \mathrm{BF}_{20} \mathrm{MnN}_{9} \mathrm{O}_{8}$ : C, 53.62; $\mathrm{H}$, $3.00 ;$ N, 7.82. Found: C, 53.46; H, 2.67; N, 7.38. $\lambda_{\max }(\mathrm{Q}-$ peak) $=820 \mathrm{~nm}$.

$\left.{ }^{\text {Eto }} \boldsymbol{P c M n N}\right]\left[\boldsymbol{B}\left(\boldsymbol{C}_{6} \boldsymbol{F}_{5}\right)_{4}\right]_{2}\left(2^{2+}\right)$. In a glovebox, $0.020 \mathrm{~g}(0.0214$ mmol) of 2 was dissolved in $\sim 7.5 \mathrm{~mL}$ of DCM. [(4$\left.\left.\mathrm{BrC}_{6} \mathrm{H}_{4}\right)_{3} \mathrm{~N}\right]\left[\mathrm{B}\left(\mathrm{C}_{6} \mathrm{~F}_{5}\right)_{4}\right](49.7 \mathrm{mg}, 0.0428 \mathrm{mmol}, 2$ eq. $)$ was dissolved in $\sim 2.5 \mathrm{~mL}$ of DCM, which was added dropwise to the green DCM solution of $\mathbf{2}$ under stirring, turning the solution deep fuchsia. The solution was stirred for $5 \mathrm{mins}$, then reduced to dryness under reduced pressure. Benzene $(15 \mathrm{~mL})$ was added, and the solution was stirred for an additional 10 mins. The slurry was filtered through a glass wool Celite ${ }^{\circledR}$ plug resulting in a light blue effluent and dark powder on the plug. The powder was extracted with DCM, resulting in a deep fuchsia solution. The solution was pumped to dryness, resulting in dark purple microcrystals that were stored at $-40{ }^{\circ} \mathrm{C}$. Recrystallizations were performed by layering in fluorobenzene with benzene at room temperature, resulting in rectangular purple crystals. Yield: $0.031 \mathrm{~g}(64.0 \%) .{ }^{1} \mathrm{H} \mathrm{NMR}\left(400 \mathrm{MHz}, \mathrm{CD}_{2} \mathrm{Cl}_{2}\right): \delta 7.51(\mathrm{~s}, 8 \mathrm{H}$, $\left.\mathrm{C}_{6} \mathrm{H}_{2}\right), 4.60\left(\mathrm{q}, J=7.0 \mathrm{~Hz}, 16 \mathrm{H}, \mathrm{OCH}_{2} \mathrm{CH}_{3}\right), 1.60(\mathrm{t}, J=7.0 \mathrm{~Hz}$, $24 \mathrm{H}, \mathrm{OCH}_{2} \mathrm{CH}_{3}$ ). ${ }^{13} \mathrm{C}\left\{{ }^{1} \mathrm{H}\right\} \mathrm{NMR}$ (low signal/noise): $\delta 149.7$, 147.2, 137.8, 135.5, 130.4, 128.7, 115.5, 67.3, 15.1. ${ }^{11} \mathrm{~B}\left\{{ }^{1} \mathrm{H}\right\}$ NMR: $\delta$-16.7 (s). ${ }^{19} \mathrm{~F}\left\{{ }^{1} \mathrm{H}\right\}$ NMR: $\delta 133.2(\mathrm{bs}), 163.6(\mathrm{t}), 167.5$ (bs). Anal. Calc. for $\mathrm{C}_{96} \mathrm{H}_{48} \mathrm{~B}_{2} \mathrm{~F}_{40} \mathrm{MnN}_{9} \mathrm{O}_{8}$ : C, 50.31; H, 2.11; $\mathrm{N}, 5.50$. Found: $\mathrm{C}, 50.70 ; \mathrm{H}, 1.91 ; \mathrm{N}, 5.24 . \lambda_{\max }(\mathrm{Q}-$ peak $)=832$ $\mathrm{nm}$.

[K(kryp)][ ${ }^{\text {Eto }}$ PcMnN] (2-). In a glovebox, $0.050 \mathrm{~g}(0.0535$ mmol) of 2 was dissolved in $\sim 7.5 \mathrm{~mL}$ of THF with $0.022 \mathrm{~g}$ (0.0588 mmol, 1.1 eq.) of Kryptofix ${ }^{\circledR} 222 . \mathrm{KC}_{8}(0.0072 \mathrm{~g}$, $0.0533 \mathrm{mmol}, 1$ eq.) was slurried in THF and added dropwise to the green solution of $\mathbf{2}$ under stirring, turning the solution deep teal. The solution was stirred for $10 \mathrm{mins}$, then reduced to dryness under vacuum. Benzene $(10 \mathrm{~mL})$ was added, and the solution stirred for 15 mins, resulting in a dark green/teal solution that was filtered through a glass wool Celite ${ }^{\circledR}$ plug resulting in a deep green/teal effluent and dark powder on the plug. The product was extracted with THF, resulting in a dark teal effluent which was then reduced to dryness to yield the microcrystalline product. Recrystallizations were performed by layering in THF with isooctane at $-30{ }^{\circ} \mathrm{C}$, resulting in small, trapezoidal purple/blue crystals. Yield $0.010 \mathrm{~g}(13.9 \%) .{ }^{1} \mathrm{H}$ NMR (400 MHz, $\left.\mathrm{d}_{8}-\mathrm{THF}\right)$ : Silent with the exception of trace signals of $2^{2-}$ present. Anal. Calc. for $\mathrm{C}_{66} \mathrm{H}_{84} \mathrm{KMnN}_{11} \mathrm{O}_{14}$ : C, 58.74; $\mathrm{H}$, 6.27; N, 11.42. Found: C, 58.87; H, 6.37; N, 11.33. $\lambda_{\max }(\mathrm{Q}-$ peak $)=751 \mathrm{~nm}$.

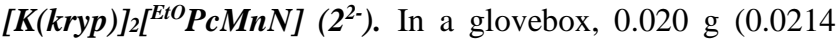
$\mathrm{mmol}$ ) of 2 was dissolved in $\sim 7.5 \mathrm{~mL}$ of THF with $0.017 \mathrm{~g}$ (0.0454 mol, 2.1 eq.) of Kryptofix ${ }^{\circledR} 222 . \mathrm{KC}_{8}(0.0145 \mathrm{~g}, 0.107$ mol, 5 eq.) was slurried in THF and added dropwise to the green solution of $\mathbf{2}$ under stirring, turning the solution deep blue. The 
solution was stirred for 10 mins, then reduced to dryness under vacuum. Hexane $(10 \mathrm{~mL})$ was added, and the solution stirred for 15 mins, resulting in a dark blue suspension that was filtered through a glass wool, Celite ${ }^{\circledR}$ plug, resulting in a clear effluent and dark microcrystalline product on the plug. The product was extracted with THF, resulting in a dark blue effluent which was then reduced to dryness to yield the microcrystalline product. Recrystallizations were performed by layering a concentrated THF solution with isooctane at $-30{ }^{\circ} \mathrm{C}$ resulting in large, sawtooth purple/blue crystals. Yield $0.016 \mathrm{~g}(42.3 \%)$. ${ }^{1} \mathrm{H}$ NMR $(600$ $\mathrm{MHz}, \mathrm{C}_{6} \mathrm{D}_{6}$ ): $\delta 6.30$ (bs, 24H, kryp), 5.79 (bs, 24H, kryp), 4.53 (s, 8H, $\mathrm{C}_{6} H_{2}$ ), 4.29 (bs, 24H, kryp), 2.53 (ddq, $J=69.0,10.6$, $\left.7.0 \mathrm{~Hz}, 16 \mathrm{H}, \mathrm{OCH}_{2} \mathrm{CH}_{3}\right), 0.64\left(\mathrm{t}, J=7.0 \mathrm{~Hz}, 24 \mathrm{H}, \mathrm{OCH}_{2} \mathrm{CH}_{3}\right)$. Anal. Calc. for $\mathrm{C}_{84} \mathrm{H}_{120} \mathrm{~K}_{2} \mathrm{MnN}_{13} \mathrm{O}_{20}: \mathrm{C}, 57.16 ; \mathrm{H}, 6.85 ; \mathrm{N}$, 10.32. Found: C, 56.95; H, 6.73; N, 10.06. $\lambda_{\max }(\mathrm{Q}-$ peak $)=699$ $\mathrm{nm}$.

\section{ASSOCIATED CONTENT}

Supporting Information. NMR, EPR, UV-Vis, FT-IR, DFT, electrochemical data, and crystallographic CIF files. This material is available free of charge via the Internet at http://pubs.acs.org.

\section{AUTHOR INFORMATION}

\section{Corresponding Author}

*Email: menard@chem.ucsb.edu

\section{Notes}

The authors declare no competing financial interests.

\section{ACKNOWLEDGMENTS}

We thank the University of California, Santa Barbara and the California NanoSystems Institute (CNSI) Challenge Grant program for financial support. NSF's ChemMatCARS Sector 15 is principally supported by the Divisions of Chemistry (CHE) and Materials Research (DMR), National Science Foundation, under grant number NSF/CHE-1346572. Use of the Advanced Photon Source, an Office of Science User Facility operated for the U.S. Department of Energy (DOE) Office of Science by Argonne National Laboratory, was supported by the U.S. DOE under Contract No. DE-AC0206CH11357. Prof. Lior Sepunaru is thanked for helpful discussions.

\section{REFERENCES}

1. Pawlicki, M.; Latos-Grażyński, L. Aromaticity Switching in Porphyrinoids. Chemistry - An Asian Journal 2015, 10, 1438-1451.

2. Wu, J. I.; Fernández, I.; Schleyer, P. v. R. Description of Aromaticity in Porphyrinoids. J. Am. Chem. Soc. 2013, 135, 315-321.

3. Herges, R. Topology in Chemistry: Designing Möbius Molecules. Chem. Rev. 2006, 106, 4820-4842.

4. Vogel, E., The porphyrins from the 'annulene chemist's' perspective. In Pure and Applied Chemistry, 1993; Vol. 65, p 143.

5. Lash, T. D. Origin of aromatic character in porphyrinoid systems. J. Porphyrins Phthalocyanines 2011, 15, 1093-1115.

6. Sondheimer, F.; Wolovsky, R.; Amiel, Y. Unsaturated Macrocyclic Compounds. XXIII.1 The Synthesis of the Fully Conjugated Macrocyclic Polyenes Cycloöctadecanonaene ([18]Annulene),2 Cyclotetracosadodecaene ([24]Annulene), and Cyclotriacontapentadecaene ([30]Annulene). J. Am. Chem. Soc. 1962, 84, 274-284.

7. Webb, L. E.; Fleischer, E. B. The Structure of Porphine1. J. Am. Chem. Soc. 1965, 87, 667-669.

8. Janson, T. R.; Kane, A. R.; Sullivan, J. F.; Knox, K.; Kenney, M. E. Ring-current effect of the phthalocyanine ring. J. Am. Chem. Soc. 1969, 91, 5210-5214.
9. Jusélius, J.; Sundholm, D. The Aromatic Character of Magnesium Porphyrins. J. Org. Chem. 2000, 65, 5233-5237.

10. Jusélius, J.; Sundholm, D. The aromatic pathways of porphins, chlorins and bacteriochlorins. Phys. Chem. Chem. Phys. 2000, 2, 2145-2151.

11. Roncali, J. Molecular Engineering of the Band Gap of $\pi$ Conjugated Systems: Facing Technological Applications. Macromolecular Rapid Communications 2007, 28, 1761-1775.

12. Ronald, B.; Frank, W. F., Jr. Charge transport in nanoscale aromatic and antiaromatic systems. Journal of Physics: Condensed Matter 2008, 20, 374104.

13. Breslow, R.; Murayama, D. R.; Murahashi, S.; Grubbs, R. Quantitative assessment of the antiaromatic city of cyclobutadiene by electrochemical studies on quinone derivatives. J. Am. Chem. Soc. 1973, 95, 6688-6699.

14. Chen, W.; Li, H.; Widawsky, J. R.; Appayee, C.; Venkataraman, L.; Breslow, R. Aromaticity Decreases SingleMolecule Junction Conductance. J. Am. Chem. Soc. 2014, 136, 918920.

15. Fujii, S.; Marqués-González, S.; Shin, J.-Y.; Shinokubo, H.; Masuda, T.; Nishino, T.; Arasu, N. P.; Vázquez, H.; Kiguchi, M. Highly-conducting molecular circuits based on antiaromaticity. Nat. Сотmun. 2017, 8, 15984.

16. Gardberg, A. S.; Doan, P. E.; Hoffman, B. M.; Ibers, J. A. Singly and Doubly Oxidized Phthalocyanine (pc) Rings: $[\mathrm{Cu}(\mathrm{pc})(\mathrm{ReO} 4)]$ and $[\mathrm{Cu}(\mathrm{pc})(\mathrm{ReO} 4) 2]$. Angew. Chem. Int. Ed. 2001, 40, 244-246.

17. Cissell, J. A.; Vaid, T. P.; Rheingold, A. L. An Antiaromatic Porphyrin Complex: Tetraphenylporphyrinato(silicon)(L)2 (L = THF or Pyridine). J. Am. Chem. Soc. 2005, 127, 12212-12213.

18. Cissell, J. A.; Vaid, T. P.; DiPasquale, A. G.; Rheingold, A. L. Germanium Phthalocyanine, GePc, and the Reduced Complexes $\mathrm{SiPc}($ pyridine)2 and $\mathrm{GePc}$ (pyridine)2 Containing Antiaromatic $\pi$ Electron Circuits. Inorg. Chem. 2007, 46, 7713-7715.

19. Cissell, J. A.; Vaid, T. P.; Yap, G. P. A. Reversible Oxidation State Change in Germanium(tetraphenylporphyrin) Induced by a Dative Ligand: Aromatic GeII(TPP) and Antiaromatic GeIV(TPP)(pyridine)2. J. Am. Chem. Soc. 2007, 129, 7841-7847.

20. Wong, E. W. Y.; Walsby, C. J.; Storr, T.; Leznoff, D. B. Phthalocyanine as a Chemically Inert, Redox-Active Ligand: Structural and Electronic Properties of a $\mathrm{Nb}(\mathrm{IV})$-Oxo Complex Incorporating a Highly Reduced Phthalocyanine(4-) Anion. Inorg. Chem. 2010, 49, 3343-3350.

21. Zhou, W.; Platel, R. H.; Teixeira Tasso, T.; Furuyama, T.; Kobayashi, N.; Leznoff, D. B. Reducing zirconium(iv) phthalocyanines and the structure of a Pc4-Zr complex. Dalton Trans. 2015, 44, 13955-13961.

22. Yamamoto, Y.; Yamamoto, A.; Furuta, S.-y.; Horie, M.; Kodama, M.; Sato, W.; Akiba, K.-y.; Tsuzuki, S.; Uchimaru, T.; Hashizume, D.; Iwasaki, F. Synthesis and Structure of $16 \pi$ Octaalkyltetraphenylporphyrins. J. Am. Chem. Soc. 2005, 127, 1454014541.

23. Yamamoto, Y.; Hirata, Y.; Kodama, M.; Yamaguchi, T.; Matsukawa, S.; Akiba, K.-y.; Hashizume, D.; Iwasaki, F.; Muranaka, A.; Uchiyama, M.; Chen, P.; Kadish, K. M.; Kobayashi, N. Synthesis, Reactions, and Electronic Properties of $16 \pi$-Electron Octaisobutyltetraphenylporphyrin. J. Am. Chem. Soc. 2010, 132, 12627-12638.

24. Sugawara, S.; Hirata, Y.; Kojima, S.; Yamamoto, Y.; Miyazaki, E.; Takimiya, K.; Matsukawa, S.; Hashizume, D.; Mack, J.; Kobayashi, N.; Fu, Z.; Kadish, K. M.; Sung, Y. M.; Kim, K. S.; Kim, D. Synthesis, Characterization, and Spectroscopic Analysis of Antiaromatic Benzofused Metalloporphyrins. Chem. Eur. J. 2012, 18, 3566-3581.

25. Cissell, J. A.; Vaid, T. P.; Yap, G. P. A. The Doubly Oxidized, Antiaromatic Tetraphenylporphyrin Complex [Li(TPP)][BF4]. Org. Lett. 2006, 8, 2401-2404.

26. Xie, D.; Liu, Y.; Rao, Y.; Kim, G.; Zhou, M.; Yu, D.; Xu, L.; Yin, B.; Liu, S.; Tanaka, T.; Aratani, N.; Osuka, A.; Liu, Q.; Kim, D.; Song, J. meso-Triaryl-Substituted Smaragdyrins: Facile 
Aromaticity Switching. J. Am. Chem. Soc. 2018, DOI: 10.1021/jacs.8b07973.

27. Cook, M. J.; Dunn, A. J.; Howe, S. D.; Thomson, A. J.; Harrison, K. J. Octa-alkoxy phthalocyanine and naphthalocyanine derivatives: dyes with Q-band absorption in the far red or near infrared. J. Chem. Soc. Perkin Trans. 1 1988, 2453-2458.

28. Contakes, S. M.; Beatty, S. T.; Dailey, K. K.; Rauchfuss, T. B.; Fenske, D. $\pi$-Complexes of Phthalocyanines and Metallophthalocyanines. Organometallics 2000, 19, 4767-4774.

29. Leznoff, C. C.; Lever, A. B. P., Phthalocyanines: Properties and Applications. Wiley VCH: New York, NY, 1989.

30. Wang, H.-H.; Yuan, H.-Q.; Mahmood, M. H. R.; Jiang, Y.Y.; Cheng, F.; Shi, L.; Liu, H.-Y. Crystal structure, magnetic and catalytic oxidation properties of manganese(iii) tetrakis(ethoxycarbonyl)porphyrin. RSC Advances 2015, 5, 9739197399.

31. Evans, D. F. 400. The determination of the paramagnetic susceptibility of substances in solution by nuclear magnetic resonance. J. Chem. Soc. 1959, 2003-2005.

32. Keener, M.; Peterson, M.; Hernández Sánchez, R.; Oswald, V. F.; Wu, G.; Ménard, G. Towards Catalytic Ammonia Oxidation to Dinitrogen: A Synthetic Cycle by Using a Simple Manganese Complex. Chem. Eur. J. 2017, 23, 11479-11484.

33. Du Bois, J.; Tomooka, C. S.; Hong, J.; Carreira, E. M. Nitridomanganese $(\mathrm{V})$ Complexes: Design, Preparation, and Use as Nitrogen Atom-Transfer Reagents. Acc. Chem. Res. 1997, 30, 364-372.

34. Du Bois, J.; Hong, J.; Carreira, E. M.; Day, M. W. Nitrogen Transfer from a Nitridomanganese(V) Complex: Amination of Silyl Enol Ethers. J. Am. Chem. Soc. 1996, 118, 915-916.

35. Frick, K.; Verma, S.; Sundermeyer, J.; Hanack, M. Novel Nitrido- and Oxo(phthalocyaninato) Complexes of Molybdenum, Tungsten and Rhenium. Eur. J. Inorg. Chem. 2000, 2000, 1025-1030.

36. Goedkent, V. L.; Ercolani, C. Nitrido-bridged iron phthalocyanine dimers: synthesis and characterization. J. Chem. Soc., Chem. Commun. 1984, 378-379.

37. Kudrik, E. V.; Afanasiev, P.; Sorokin, A. B. Synthesis and Properties of FeIII-N=MnIV Heterometallic Complex with Tetra-tertbutylphthalocyanine Ligands. Macroheterocycles 2010, 3, 19-22.

38. Donzello, M. P.; Ercolani, C.; Russo, U.; Chiesi-Villa, A.; Rizzoli, C. Metal- and Ligand-Centered Monoelectronic Oxidation of $\mu-$

Nitrido[((tetraphenylporphyrinato)manganese)(phthalocyaninatoiron)] , [(TPP)Mn-N-FePc]. X-ray Crystal Structure of the $\mathrm{Fe}(\mathrm{IV})$ Containing Species [(THF)(TPP)Mn-N-FePc(H2O)](I5) 2 THF. Inorg. Chem. 2001, 40, 2963-2967.

39. Grunewald, H.; Homborg, H. Preparation and Spectroscopical Characterization of Nitridophthalocyaninatomanganese(V). Z. Naturforsch., B 1990, 45b, 483-489.

40. Grunewald, H.; Homborg, H. Darstellung und Charakterisierung von $\operatorname{Chrom}(\mathrm{V})-$ und Mangan(V)nitridophthalocyaninen(1-) und -(2-): [MNPc(1-)]+; und $[\mathrm{MNPc}(2-)]$ (M=Cr, Mn). Z. Anorg. Allg. Chem. 1992, 608, 81-87.

41. Shields, M. R.; Guzei, I. A.; Goll, J. G. Crystal structure of nitrido[5,10,15,20-tetrakis(4-

methylphenyl)porphyrinato]manganese(V). Acta Cryatallogr. E 2014, $70,242-245$.

42. Ho, C.-M.; Lau, T.-C.; Kwong, H.-L.; Wong, W.-T. Activation of manganese nitrido complexes by Bronsted and Lewis acids. Crystal structure and asymmetric alkene aziridination of a chiral salen manganese nitrido complex. J. Chem. Soc. Dalton Trans. 1999, 2411-2414.

43. Kropp, H.; King, A. E.; Khusniyarov, M. M.; Heinemann, F. W.; Lancaster, K. M.; DeBeer, S.; Bill, E.; Meyer, K. Manganese Nitride Complexes in Oxidation States III, IV, and V: Synthesis and Electronic Structure. J. Am. Chem. Soc. 2012, 134, 15538-15544.

44. Engel, M. K., 122 - Single-Crystal Structures of Phthalocyanine Complexes and Related Macrocycles A2 - Kadish, Karl M. In The Porphyrin Handbook, Smith, K. M.; Guilard, R., Eds. Academic Press: Amsterdam, 2003; pp 1-242.
45. Cissell, J. A.; Vaid, T. P.; Rheingold, A. L. Aluminum Tetraphenylporphyrin and Aluminum Phthalocyanine Neutral Radicals. Inorg. Chem. 2006, 45, 2367-2369.

46. Wong, E. W. Y.; Leznoff, D. B. Synthesis and structural characterization of a magnesium phthalocyanine(3-) anion. $J$. Porphyrins Phthalocyanines 2012, 16, 154-162.

47. Konarev, D. V.; Kuzmin, A. V.; Faraonov, M. A.; Ishikawa, M.; Khasanov, S. S.; Nakano, Y.; Otsuka, A.; Yamochi, H.; Saito, G.; Lyubovskaya, R. N. Synthesis, Structures, and Properties of Crystalline Salts with Radical Anions of Metal-Containing and Metal-Free Phthalocyanines. Chem. Eur. J. 2015, 21, 1014-1028.

48. Zhou, W.; Thompson, J. R.; Leznoff, C. C.; Leznoff, D. B. The Redox-Active Chromium Phthalocyanine System: Isolation of Five Oxidation States from Pc4-CrI to Pc2-CrIII. Chem. Eur. J. 2017, 23, 2323-2331.

49. O'Connor, A. R.; Nataro, C.; Golen, J. A.; Rheingold, A. L. Synthesis and reactivity of $[\mathrm{N}(\mathrm{C} 6 \mathrm{H} 4 \mathrm{Br}) 3][\mathrm{B}(\mathrm{C} 6 \mathrm{~F} 5) 4]$ : the $\mathrm{X}$-ray crystal structure of $[\mathrm{Fe}(\mathrm{C} 5 \mathrm{H} 5) 2][\mathrm{B}(\mathrm{C} 6 \mathrm{~F} 5) 4]$. J. Organomet. Chem. 2004, 689, 2411-2414.

50. Connelly, N. G.; Geiger, W. E. Chemical Redox Agents for Organometallic Chemistry. Chem. Rev. 1996, 96, 877-910.

51. Lalancette, J. M.; Rollin, G.; Dumas, P. Metals Intercalated in Graphite. I. Reduction and Oxidation. Can. J. Chem. 1972, 50, 30583062 .

52. Clarke, R. M.; Storr, T. Tuning Electronic Structure To Control Manganese Nitride Activation. J. Am. Chem. Soc. 2016, 138, 15299-15302.

53. Leeladee, P.; Baglia, R. A.; Prokop, K. A.; Latifi, R.; de Visser, S. P.; Goldberg, D. P. Valence Tautomerism in a High-Valent Manganese-Oxo Porphyrinoid Complex Induced by a Lewis Acid. $J$. Am. Chem. Soc. 2012, 134, 10397-10400.

54. Robertson, J. M.; Woodward, I. 37. An X-ray study of the phthalocyanines. Part III. Quantitative structure determination of nickel phthalocyanine. J. Chem. Soc. 1937, 219-230.

55. Ziolo, R. F.; Griffiths, C. H.; Troup, J. M. Crystal structure of vanadyl phthalocyanine, phase II. J. Chem. Soc. Dalton Trans. 1980, 2300-2302

56. Ukei, K. Lead phthalocyanine. Acta Crystallogr., Sect. B: Struct. Sci. 1973, 29, 2290-2292.

57. Friedel, M. K.; Hoskins, B. F.; Martin, R. L.; Mason, S. A. A new metal(II) phthalocyanine structure: X-ray and Mossbauer studies of the triclinic tin(II) phthalocyanine. J. Chem. Soc. D. 1970, 400-401.

58. Chambrier, I.; J. Cook, M.; T. Wood, P. Conformationally stressed phthalocyanines: the non-planarity of the 1,4,8,11,15,18,22,25-octaisopentyl derivative. Chem. Commun. 2000, $2133-2134$

59. Kobayashi, N.; Fukuda, T.; Ueno, K.; Ogino, H. Extremely Non-Planar Phthalocyanines with Saddle or Helical Conformation: Synthesis and Structural Characterizations. J. Am. Chem. Soc. 2001, 123, 10740-10741.

60. Mack, J.; Kobayashi, N. Low Symmetry Phthalocyanines and Their Analogues. Chem. Rev. 2011, 111, 281-321.

61. Fukuda, T.; Homma, S.; Kobayashi, N. Deformed Phthalocyanines: Synthesis and Characterization of Zinc Phthalocyanines Bearing Phenyl Substituents at the 1-, 4-, 8-, 11-, 15-, 18-, 22-, and/or 25-Positions. Chem. Eur. J. 2005, 11, 5205-5216.

62. Allen, F. H.; Kennard, O.; Watson, D. G.; Brammer, L.; Orpen, A. G.; Taylor, R. Tables of bond lengths determined by X-ray and neutron diffraction. Part 1. Bond lengths in organic compounds. $J$. Chem. Soc., Perkin Trans. 2 1987, S1-S19.

63. Gershoni-Poranne, R.; Stanger, A. Magnetic criteria of aromaticity. Chem. Soc. Rev. 2015, 44, 6597-6615.

64. Mitchell, R. H. Measuring Aromaticity by NMR. Chem. Rev. 2001, 101, 1301-1316.

65. Gomes, J. A. N. F.; Mallion, R. B. Aromaticity and Ring Currents. Chem. Rev. 2001, 101, 1349-1384.

66. Pople, J. A.; Untch, K. G. Induced Paramagnetic Ring Currents. J. Am. Chem. Soc. 1966, 88, 4811-4815. 
67. Peeks, M. D.; Claridge, T. D. W.; Anderson, H. L. Aromatic and antiaromatic ring currents in a molecular nanoring. Nature 2016, 541,200

68. Fieser, M. E.; MacDonald, M. R.; Krull, B. T.; Bates, J. E.; Ziller, J. W.; Furche, F.; Evans, W. J. Structural, Spectroscopic, and Theoretical Comparison of Traditional vs Recently Discovered Ln2+ Ions in the $[\mathrm{K}(2.2 .2$-cryptand $)][(\mathrm{C} 5 \mathrm{H} 4 \mathrm{SiMe} 3) 3 \mathrm{Ln}]$ Complexes: The Variable Nature of Dy2+ and Nd2+. J. Am. Chem. Soc. 2015, 137, 369382.

69. Hirakawa, F.; Ichikawa, H.; Ishida, S.; Iwamoto, T. Redox Reactions of a Stable Dialkylphosphinyl Radical. Organometallics 2015, 34, 2714-2716.

70. Hernández Sánchez, R.; Bartholomew, A. K.; Powers, T. M.; Ménard, G.; Betley, T. A. Maximizing Electron Exchange in a [Fe3] Cluster. J. Am. Chem. Soc. 2016, 138, 2235-2243.

71. We note that the $1 \mathrm{H}$ NMR spectrum of 22- was taken in C6D6 rather than DCM-d2 due to solvent incompatibility with the latter; however, we do not believe that the observed chemical shift changes are a result of solvent.

72. Minor, P. C.; Gouterman, M.; Lever, A. B. P. Electronic spectra of phthalocyanine radical anions and cations. Inorg. Chem. 1985, 24, 1894-1900.
73. Costa, R.; Schick, A. J.; Paul, N. B.; Durfee, W. S.; Ziegler, C. J. Hydroxybenziphthalocyanines: non-aromatic phthalocyanine analogues that exhibit strong UV-visible absorptions. New J. Chem. 2011, 35, 794-799.

74. Schleyer, P. v. R.; Maerker, C.; Dransfeld, A.; Jiao, H.; van Eikema Hommes, N. J. R. Nucleus-Independent Chemical Shifts: A Simple and Efficient Aromaticity Probe. J. Am. Chem. Soc. 1996, 118, 6317-6318.

75. Vaid, T. P. A Porphyrin with a $\mathrm{C}=\mathrm{C}$ Unit at Its Center. $J$. Am. Chem. Soc. 2011, 133, 15838-15841.

76. Johnson, S. M.; Paul, I. C.; King, G. S. D. [16]Annulene: the crystal and molecular structure. Journal of the Chemical Society B: Physical Organic 1970, 643-649.

77. Gorter, S.; Rutten-Keulemans, E.; Krever, M.; Romers, C.; Cruickshank, D. W. J. [18]-Annulene, C18H18, structure, disorder and Huckel's $4 n+2$ rule. Acta Crystallogr., Sect. B: Struct. Sci. 1995, 51, 1036-1045.

78. Oth, J. F. M.; Woo, E. P.; Sondheimer, F. Unsaturated macrocyclic compounds. LXXXIX. Dianion of [18]annulene. J. Am. Chem. Soc. 1973, 95, 7337-7345.

Authors are required to submit a graphic entry for the Table of Contents (TOC) that, in conjunction with the manuscript title, should give the reader a representative idea of one of the following: A key structure, reaction, equation, concept, or theorem, etc., that is discussed in the manuscript. Consult the journal's Instructions for Authors for TOC graphic specifications.
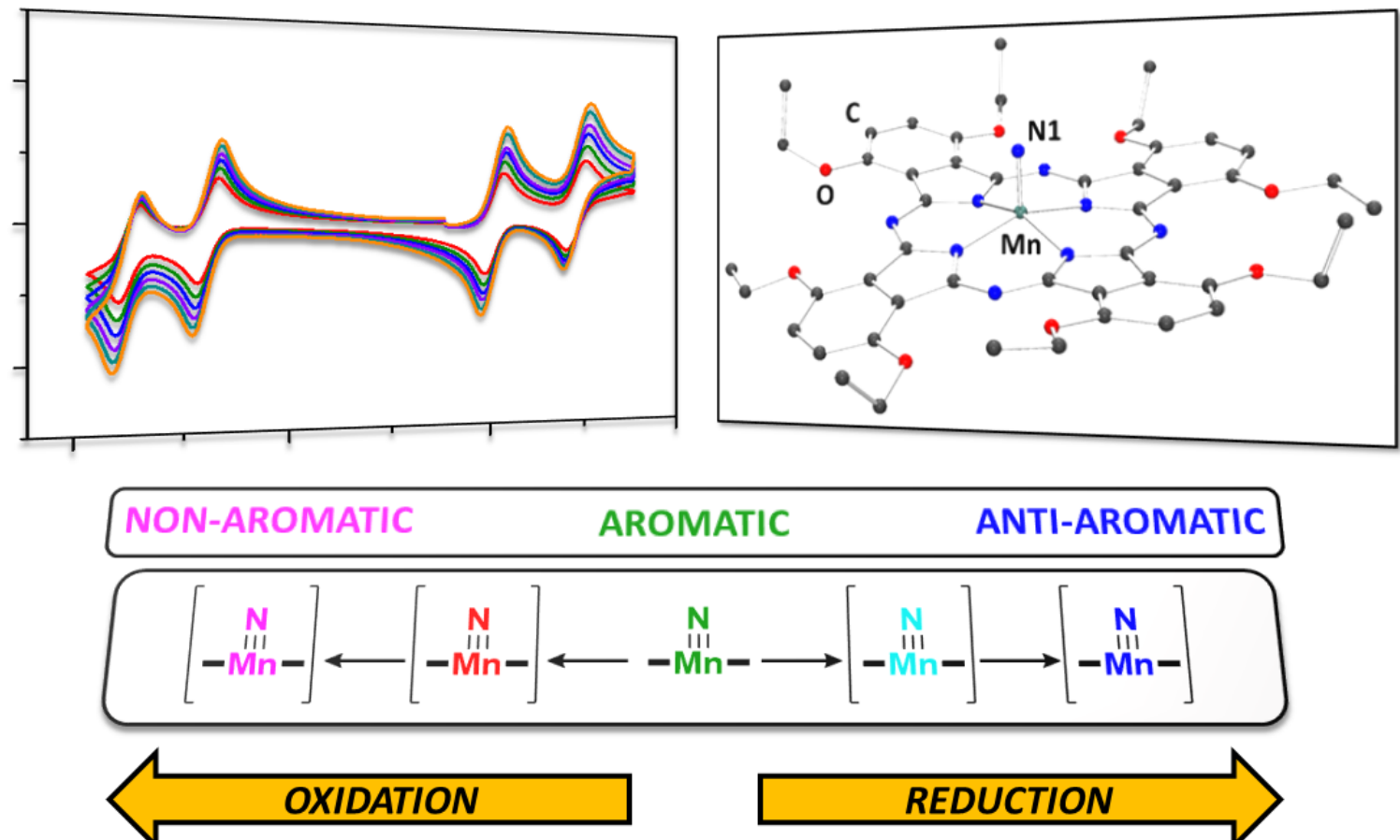

REDUCTION 